\title{
PAISAJES EDUCATIVOS: DOLOR, MARCAS Y DESGASTES DE LOS CUERPOS EN UNA PLANTADE PRODUCCIÓN
}

\section{EDUCATIONAL LANDSCAPES: PAIN, MARKS AND BODY WEAR IN A PRODUCTION PLANT}

\section{Leidy Yaneth Vásquez Ramírez ${ }^{1}$}

\section{Teresita Ospina Álvarez²}

\section{Edilberto Hernández González ${ }^{3}$}

Universidad de San Buenaventura

\footnotetext{
$1 \quad$ Doctora en Ciencias de la Educación de la Universidad de San Buenaventura, Medellín, en la línea: Estudios culturales y Lenguajes Contemporáneos. Profesora cátedra de la Universidad de Antioquia, integrante de los grupos de investigación ESINED (Universidad de San Buenaventura- Medellín) y Gepidh (Universidad de Antioquia). Contacto: Iyaneth.vasquez@udea.edu.co; ORCID: http:// orcid.org/0000-0002-1090-7234.

Dirección: Cra. 30A \# 32B-26, apto 201. Medellín, Colombia. 2 Doctora en Educación de la Universidad de Antioquia. Profesora del Doctorado en Ciencias de la Educación de la Universidad San Buenaventura, Medellín. Investigadora de la línea: Estudios culturales y Lenguajes Contemporáneos. Grupo de Investigación ESINED.

Contacto: teresita.ospina@usbmed.edu.co;

ORCID: http://orcid.org/0000-0002-7725-491X Dirección: Cra. 70 No. 1 -60. Medellín, Colombia.

3 Doctor en Educación de la Universidad de la Salle, Costa Rica. Profesor del Doctorado en Ciencias de la Educación de la Universidad San Buenaventura, Medellín. Investigador de la línea: Estudios culturales y Lenguajes Contemporáneos. Grupo de Investigación ESINED. Contacto: edilberto.hernandez@usbmed.edu.co; ORCID: http:// orcid.org/0000-0002-6274-4078 Dirección: Cra. 83A No. 37B - 17 Interior 208. Medellín, Colombia.
}

\section{RESUMEN}

Este artículo presenta una cartografía de la industrialización del dolor, de las marcas y del desgaste de los cuerpos en una planta de producción, donde se diseña, imprime y encuaderna material educativo; cuyos propósitos estuvieron dirigidos a componer paisajes subjetivos en la cotidianidad de una planta de producción y lo que ella va fabricando en los cuerpos; así mismo, experimentar con mapas de intensidades, discontinuidades, devenires y aconteceres de los cuerpos en la cotidianidad de la planta; y, crear-inventar una serie de narraciones-poemas-líneas, en las que se devela la producción de subjetividades 
en clave de formación en la cotidianidad, por fuera de la institucionalidad escolar. El estudio se fundamentó teórica y metodológicamente en las filosofías de la diferencia, escenario en el que se compuso un método cartográfico en cuatro momentos: el primero: Habitar la planta; el segundo: la expansión de los cuerpos, encuentros-conversaciones; el tercero: acontecer paisaje, realización de las actividades de la producción; $y$, el cuarto momento: experimentación-creación de conocimiento. A través de estas acciones, se pudo establecer que, la actividad productiva desarrollada en la planta de producción, posee intensidades que se registran en forma de cicatrices, deformaciones y dolencias crónicas, constituyendo así, una experiencia corporal en términos de cuerposmáquinas y subjetividades eco-empresariales. Percibimos, además, la configuración de una gramática del cansancio que recorre los espacios de la planta y la vida cotidiana de las operarias; haciéndose presente unos cuerpos que resisten y que crean en el interior de una planta de producción ubicada en la ciudad de Medellín.

\section{PALABRAS CLAVE:}

cuerpos-máquinas; cartografía; educación (otras); cuerpos industrializados; espaciospaisajes.

\section{SUMMARY}

This article presents a cartography of the industrialization of pain, of brands and the wear of the bodies in a production plant, where it is designed, printed and bind educational material; whose purposes were aimed at composing landscapes subjective factors in the daily life of a production plant and what it is manufacturing in the bodies; likewise, experiment with maps of intensities, discontinuities, becoming and events of the bodies in the daily life of the plant; and, create-invent a series of narrations-poems- lines, in which the production of subjectivities in the key of training in everyday life, outside the school institution. The study was theoretically and methodologically based on the philosophies of difference, scenario in the that a cartographic method was composed in four moments: the first: inhabiting the plant; the second: the expansion of bodies, meetings-conversations; the third: to happen landscape, realization of production activities; and the fourth moment: experimentation-creation of knowledge. Through these actions, it was possible to establish that the productive activity carried out in the production plant has intensities that are recorded in the form of scars, deformations and chronic ailments, thus constituting, a bodily experience in terms of machine-bodies and eco-business We also perceive the configuration of a grammar of fatigue that travels the spaces of the plant and the daily life of the operators; showing up two bodies that resist and create inside a production plant located in the city of Medellín.

\section{KEYWORDS:}

bodies-machines; mapping; education (other); industrialized bodies; spaces-landscapes.

\section{INTRODUCCIÓN}

En el presente artículo nos ocupamos de los cuerpos industrializados, del dolor, de las marcas y de los desgastes producidos en los cuerpos y en las máquinas, asuntos derivados de la investigación: Cartografías de una educación (otras) $(2019)^{4}$, cuyos propósitos estuvieron dirigidos a cartografiar lo educativo que sucede en los intersticios

$4 \quad$ Investigación articulada a la tesis doctoral "Paisajes educativos en la planta de producción: ficciografías de los cuerpos que se producen" (2021) y a procesos de conceptualización y experimentación-creación adelantados por la línea en Estudios culturales y lenguajes contemporáneos, del grupo de investigación ESINED, Universidad de San Buenaventura, Medellín; con la participación del grupo de investigación en Educación, Arte y Filosofía: Experimentaciones con arte y filosofía del Instituto Federal de Educação, Ciência e tecnología Sul-rio-grandense (IFSul), Pelotas, Brasil. 
de las arquitecturas espaciales, temporales y corporales con un grupo de mujeres que se desempeñan como operarias, en una planta de producción de materiales educativos, ubicada en el Área Metropolitana de Medellín, Colombia. Esta investigación se desarrolló entre el 2017 y el 2019, años durante los cuales se realizaron diversos tipos de encuentros, principalmente espacios de conversación individual y en pequeños grupos, dentro de los lugares y horarios laborales; también se realizaron dos temporadas de inmersión en las actividades de la planta de producción de diez días cada una, y un recorrido con las participantes, por el centro histórico de la ciudad de Medellín, recorrido en el cual compartimos diversas actividades culturales en lugares emblemáticos, hasta culminar en el campus central de la Universidad de San Buenaventura - Medellín, para participar allí de un taller artístico.

El año 2020 marca una ruptura en torno de las preguntas que hasta entonces habían acaparado asuntos importantes de nuestro relacionamiento humano global. De repente, se disloca el paisaje, un virus nos aboca -como nos lo han anunciado la literatura, el cine, las artes, en piezas tan destacadas como la fotonovela La Jeteé (1962), de Chris Marker; la película Doce monos (1995), dirigida por Terri Gilliam; o las inquietantes historias de Isaac Asimov, llevadas también al cine y la televisión, entre otros-, hacia la improvisación de maneras otras para otorgarnos una presencia corporal, precisamente, porque en este escenario global, el cuerpo se ha convertido en una amenaza, en un lugar de contagio en el que convive lo mejor y lo peor, como en un tipo de rizoma virtual de nuestras discontinuidades. Las epidemias virales que cuestionan nuestras corporalidades biológicas y virtuales, hacen cada vez más actual las preguntas por el cuerpo en el escenario de las interconexiones entre especies, objetos, sujetos humanos y no humanos, porque ponen en el centro de nuestras preguntas conceptos como: enfermedad, contagio, mutación, muerte, dolor, que ilusoriamente pensábamos controlar y con las cuales podríamos ahora crear, en muy poco tiempo, otra existencia, una educación "otra", un cuerpo "otro".

En esas palabras molestas, con las que siempre hemos convivido, pese a nuestro intento por hacerlas invitadas ausentes en nuestras vidas, vemos ahora un paisaje semántico que se abre de manera retadora, para agrietarnos con su presencia y crear un punto de fuga para lo que hasta este momento habíamos constituido como realidad y presencia en escenarios sociales, como el educativo, por ejemplo. La crisis de la asepsia corporal pone en crisis también nuestra limpieza lingüística, investigativa, e irrumpe con tal fuerza que consigue plegar nuestras maneras de relacionarnos, retomando con fuerza la urgencia de una variación de nuestras potencias propias y de las maneras como nuestros cuerpos invaden todas las dimensiones de la virtualidad, en lo que vive y muere en nosotros y en los otros, para instalar un nuevo punto de vista, en tanto condición desde la cual nos disponemos a captar: "la verdad de una variación [que] se presenta al sujeto" (Deleuze 2017, 31). Teniendo en cuenta estos movimientos y siguiendo a Braidotti (2015), Deleuze (2014) y Bal (2016), se anuncia un nuevo sentido para los estudios culturales, los cuales exploran las formas de producción y creación de las sociedades actuales proponiendo otras maneras para ocuparse de actividades cotidianas en las formaciones sociales, desde métodos viajeros:

[...] los confines entre las categorías de lo natural y lo cultural han sido desplazados $y$, en gran medida, esfumados por los efectos de los desarrollos científicos y tecnológicos [...] la teoría social necesita poner las cosas en su sitio sobre la transformación de los conceptos, los métodos y las prácticas 
políticas, causadas por tal cambio de paradigma (Braidotti 2015, 13).

Así, esta investigación, nos posibilitó posicionarnos por fuera de aquellos discursos educativos y pedagógicos tradicionalmente constituidos que centran la mirada en la transmisión y apropiación de capacidades, valores y fundamentalmente conocimientos en el contexto de la institución escolar; es así como, en este estudio, nos hemos forzado a diagramar una educación (otras), desde otros modos para comprometerse con el método y el presente de las investigaciones que están abordando preguntas alrededor de, quizá, uno de los temas más inquietantes en la contemporaneidad: el cuerpo. Este giro hacia el acercamiento a los cuerpos en producción, tal como lo señalan algunos autores (Courtine, 2014; Serres, 2011; Braidotti, 2018), es ya un aporte metodológico para la investigación y el arte. Así este artículo presenta una experiencia de producción subjetiva que se despliega en una planta de producción y desde la resignificación de la ciudad misma como escenario de tránsitos. Esta educación (otra), a la que nos referimos, se compone de espaciospaisajes; imágenes-relieves; gestos-sistemas; saberes-maquínicos; afectos-movimientos e invenciones-pensamientos (otros).

En las primeras sesiones de trabajo con las operarias de la planta de producción, quedó al descubierto la necesidad de operar con un método cartográfico vinculado con la investigación-creación y la Investigación Basada en Artes (Días e Irwin, 2013; Hernández 2008, 2013), con el cual pudiéramos mapear esos paisajes de la producción industrial, en los que se diseña, imprime y encuaderna material educativo, principalmente para el área de educación artística; en este sentido, nos interesó una "investigación viva" (Días e Irwin 2013, 29) y un método que nos permitiera experimentar; $y$, no solo documentar la pluralidad de la experiencia educativa que vislumbrábamos en este espacio.

Sabíamos que el método, tendría que situarnos a cierta distancia de la descripción etnográfica - fenomenológica de orden puramente empírico, (Berger y Luckmann 2001, 36-52) a fin de movernos a experimentar-crear, desde una perspectiva sensible que hiciera de las realidades cotidianas una experiencia, una geografía y existencial. Nuestra invención metódica, fue denominada Paisajear ${ }^{\text {, }}$ concepto con el cual designamos la acción de componer paisajes geográficos-existenciales, en el contexto de una planta de producción. En términos epistemológicos el método se apoyó en las construcciones teórica desplegadas en las filosofías de la diferencia y otros autores que se han ocupado de reflexionar en torno de investigaciones de corte pos-estructuralistas; en este sentido, para Guattari y Rolnik (2006) la cartografía permite esbozar mapas de los modos de producción de la subjetividad, dibujar las formas que toman los mecanismos de poder abriendo posibles opciones de resistencia, transgresión y proposición de nuevos mapas.

Paisajear, es entonces, un pliegue metódico que agencia una manera de cartografiar el transcurrir de la existencia en un ámbito no convencional de la educación, pero en el cual se despliega un acontecer sensible, biósfera de la experiencia de educarnos y de configuración del transcurrir de la formación. Se trata de un método, constituido por un conjunto de acciones-gestos,

$5 \quad$ "Paisajear es una composición propia, que no corresponde a un término de uso reconocido en castellano; es un término que conserva la intención de dar vida a un entramado de acciones y afecciones en el contexto de la investigación Cartografías de una educación (otras). Paisajear, paisajeo, paisajeante, nos lleva a pensar en una serie de variaciones de orden verbal, tales como acciones de tiempo (paisajeo, paisajeé, paisajarearé); de voz (paisajea); de aspecto (he paisajeado, paisajeaba); de modo (paisajeas); de número (paisajeo, paisajeamos); y funciona también como gerundio (paisajeando), en ocasiones también como adjetivo (paisajeado)". (Ospina; Hernández y Farina, 2019, p. 185). 
que no siempre comprendieron una actividad, de manera que las acciones del método unas veces activaban formas de presencia; y, otras, se tornaron actuaciones que convocaron la expansión de los cuerpos, acentuando la calidez de los encuentros, creando líneas y ensayando corrientes de fuerza. El método se desplegó a través de cuatro momentos, los cuales no siguieron una secuencia temporal, pero que fueron articulando las acciones-gestos de los investigadores en la planta de producción. Dichos momentos, fueron: habitar el paisaje; expandir el cuerpo en el paisaje; acontecer paisaje y, por último, experimentación del paisaje ${ }^{6}$.

En términos teóricos y epistemológicos, esta investigación, se fundamentó desde un conjunto de autores que se ocupan de la experiencia subjetiva (existencial), vinculada al espacio, donde el cuerpo aparece como eje articulador de la comprensión e invención de sí mismo. Esta experiencia, Deleuze, (1995) la vincula a lo múltiple $y$, cree que "la multiplicidad reside precisamente en la $\mathrm{Y}$, que es de naturaleza distinta que los elementos o los conjuntos" (Deleuze 1995, 73); así, los cuerpos industrializados podrían estar acudiendo a esta multiplicidad para desplazarse por el espacio $\mathrm{y}$ hacerse presentes desde los recorridos y movimientos que se van creando en la planta de producción; de este mismo modo, se presenta la exterioridad de las relaciones, las articulaciones y los puntos de fuga posibles en capas de movimientos de desestratificación, conjunto de acciones vinculadas al concepto denominado por Deleuze y Guattari (2012) como agenciamiento. Este concepto, precisamente, nos posibilitó entender la configuración de los cuerpos, en tanto habitantes de la planta de producción y, constituirse en un organismo para una totalidad significante. Además, Deleuze y Guattari (2012) señalan que dicho concepto:

6 El despliegue teórico, epistemológico y la configuración misma del método Paisajear, ha sido objeto de otra producción textual, de manera que no ahondaremos aquí en el tema.
También está orientado hacia un cuerpo sin órganos que no cesa de deshacer el organismo, de hacer pasar y circular partículas asignificantes, intensidades puras, de atribuirse los sujetos a los que tan sólo deja un nombre como huella de una intensidad (10).

A la luz de estas ideas, la planta de producción constituye un cuerpo orgánico, desgastado, marcado, accidentado, desprovisto de la hegemonía y limitación de los sentidos; es un cuerpo que se expone enfermo, dolorido, mutilado, abollado; pero también que es potencia, agente de unas maneras de aparecer y de habitar. Este cuerpo-planta de producción, carece de unidad, de él emergen solo fragmentos anatómicos, manos cansadas y agrietadas, brazos doloridos que reproducen la anatomía de la máquina con la que trabajan (Fotografía 1. Mano tigra en la planta de producción, febrero de 2019). Este agenciamiento corporal-colectivo que no se reduce a una identidad empresarial que suele explicar "todas las voces presentes en una voz" (Deleuze y Guattari 2012, 85), dado que el sistema industrial, de una u otra forma permanece sometido a las vicisitudes de esos cuerpos que la habitan y la recorren. 


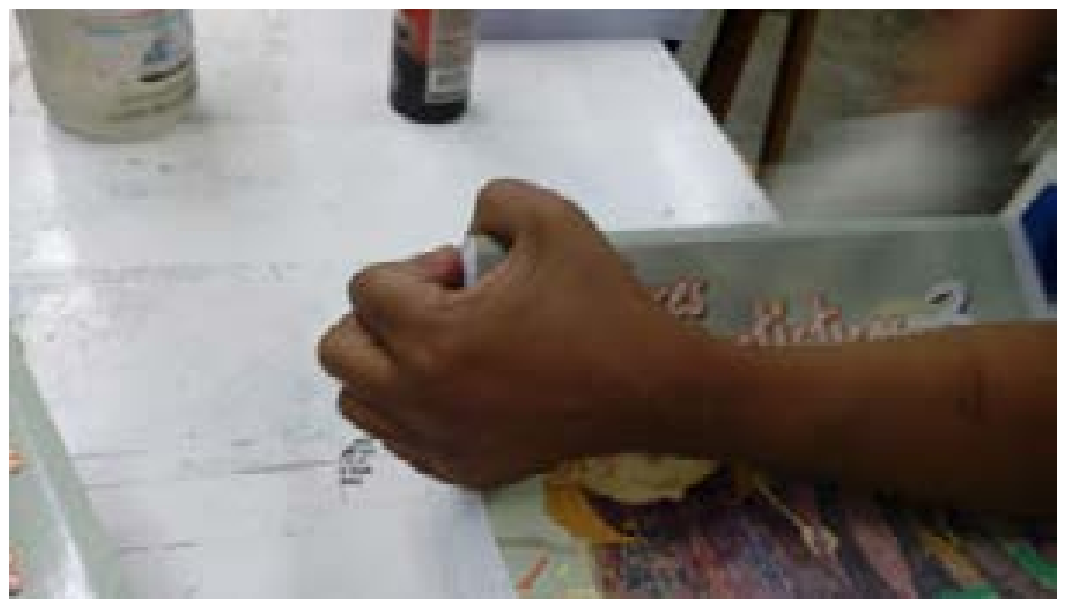

Fotografía 1. Mano tigra en la planta de producción, febrero de 2019. Archivo personal

Para nuestra investigación, la singularidad de estos movimientos se hace presente, $y$, creemos se hayan asociados a una micropolítica, centrada ya no en los grandes acontecimientos gremiales, sino en la potencia política del deseo, de la subjetividad y del encuentro con el otro; en este sentido vale la penas señalar que, la cultura de masas produjo individuos normalizados en sistemas jerárquicos que hacen coincidir la subjetividad como una disposición que puede ser llenada, pues es aquello que se produce; en Vigilar y Castigar (2002), Foucault lo sitúa en términos de una microfísica del poder, es decir, de las formas minuciosas con las que se hace adscripción política del cuerpo, y sostiene que "la disciplina es una anatomía política del detalle" (128); paralelo a ello, están aconteciendo también procesos de singularización, la producción de una subjetividad singular de la que hablan Guattari y Rolnik (2006), en la que se construye otras sensibilidades, gusto por vivir y que deviene en maneras de estar presentes en los procesos de la planta de producción (Fotografía 2. Mujer accionando la termoselladora en la planta de producción, febrero de 2019).

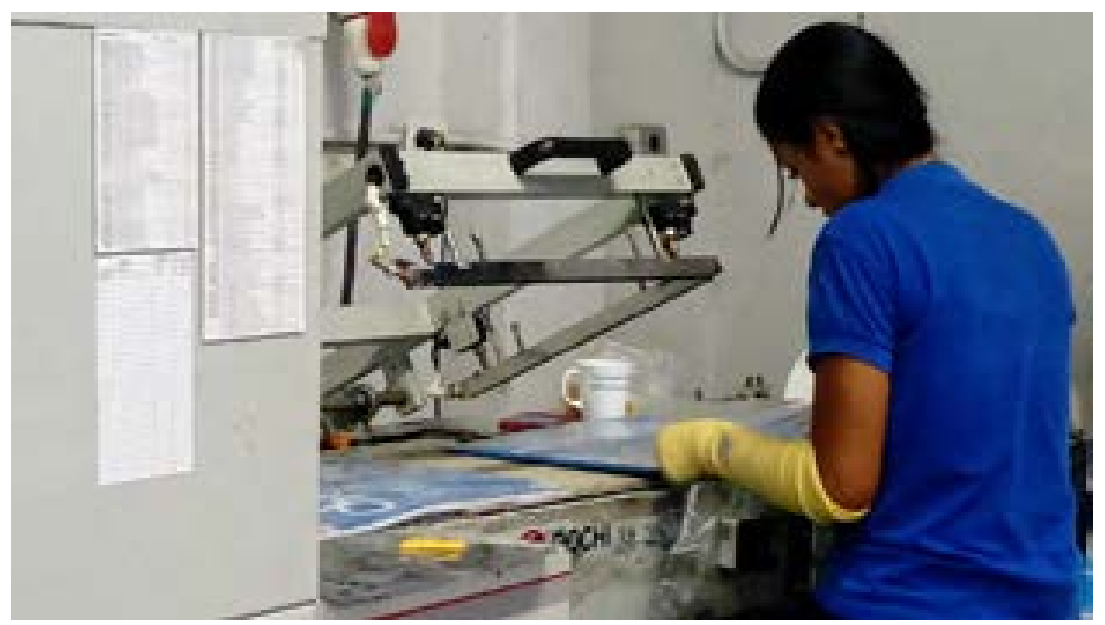

Fotografía 2. Mujer accionando la termoselladora en la planta de producción, febrero de 2019. Archivo personal. 
En el texto Post-scriptum sobre las sociedades de control, incluido en Conversaciones (1995), escrito por Gilles Deleuze, se ocupa de la idea de Foucault en relación con una genealogía del poder e indica que:

La fábrica hacía de los individuos un cuerpo, con la doble ventaja de que, en este modo, el patrono podía vigilar cada uno de los elementos que formaban la masa y los sindicatos podían movilizar a toda masa de resistentes. La empresa en cambio, instituye entre los individuos una rivalidad interminable a modo de sana competición, como una motivación excelente que contrapone unos individuos a otros y atraviesa a cada uno de ellos, dividiéndole interiormente (Deleuze 1995, 151).
De esta forma, la planta de producción en tanto institución de encierro ha mutado en la contemporaneidad, convirtiéndose en un dispositivo más sofisticado que migra hacia la idea de la organización empresarial. Organización que ofrece incentivos a sus empleados, siempre y cuando se cumpla con lo que la empresa pida. La tarea, como suele llamarse el trabajo que las operarias de la planta realizan, está compuesta por cifras que hablan del cumplimiento metas por día, semanas y meses (Fotografía 3. Registro de control de tareas, realizado por una de las mujeres de la planta de producción, marzo de 2018). Cifras que están asociadas a un tipo de productividad que genera sistemas de jerarquías y rivalidades en torno de la eficiencia.

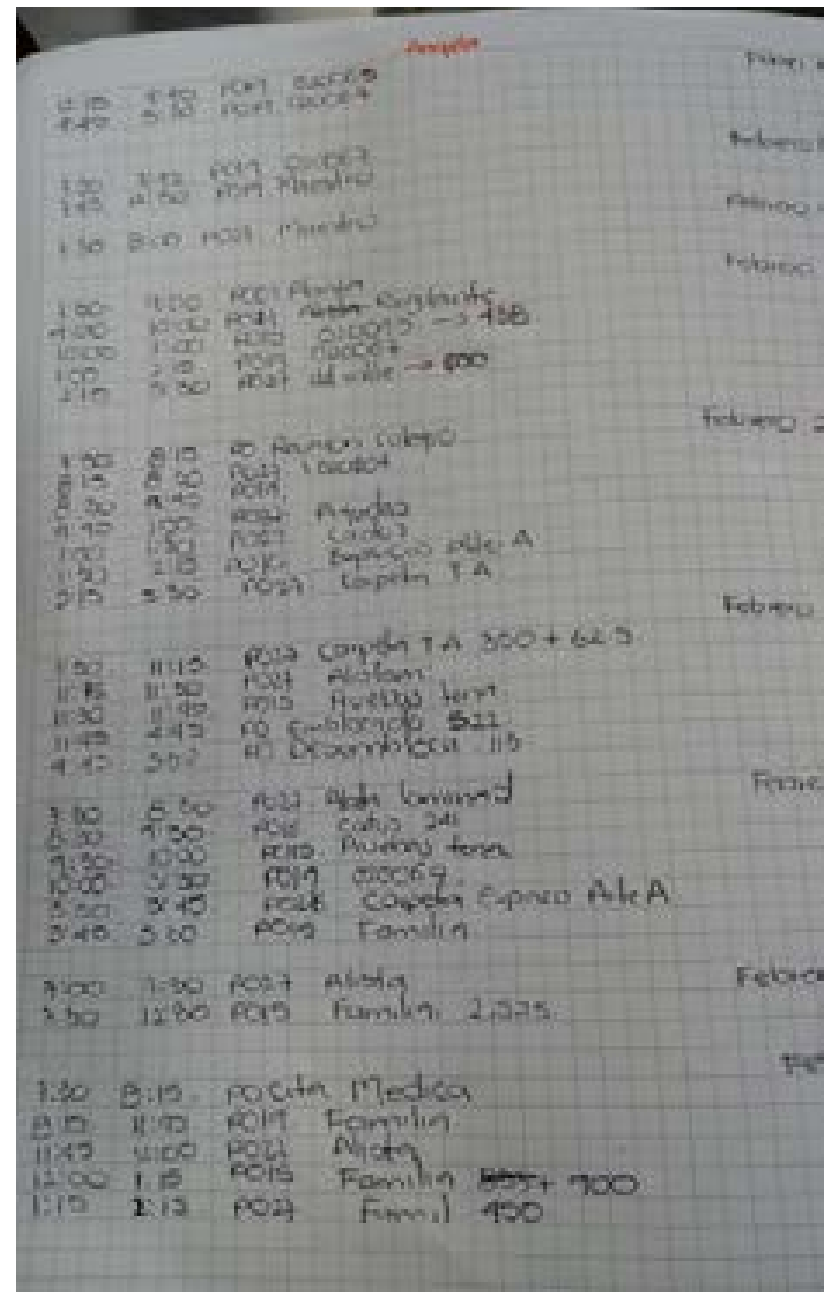

Fotografía 3. Registro de control de tareas, realizado por una de las mujeres de la planta de producción, marzo de 2018. Archivo personal. 
Tenemos conocimientos de los planes y programas de capacitación de las empresas para sus empleados; en la planta de producción, las operarias hablaban de un tiempo en que las capacitaciones eran más constantes, las reclaman en la actualidad como parte de un pasado mejor de la empresa, aunque reiteraban que lo fundamental del oficio es enseñado de unas a otras; actividad que es percibida como un proceso que nunca termina, pues aquello que saben se lo deben a quienes antes se lo compartieron; fenómeno de transmisión de saber, que coincide con la caracterización realizada por Deleuze (1995), respecto al paso de las sociedades disciplinarias a las de control, que a su vez, nos conduce a observar que las nervaduras de lo empresarial, se instauran en la planta de producción y trasciende a la cotidianidad de las casas, a la organización de la vida familiar; a un tiempo de ocio inexistente ya que apenas quedan horas para reponer la energía de unos cuerpos agotados por el trabajo.

Este agotamiento construido en la relación operaria-máquina, produce su propio cuerpo y con este la emergencia de ciertas tonalidades del dolor; entonces cabe la pregunta, ¿cómo duelen los órganos de este cuerpo? ¿Qué órganos vienen a nombrarlo? En nuestras conversaciones con las operarias de la planta de producción, el dolor transita por zonas específicas, piernas, pies y manos.

Simone Weil en la Condición obrera (2014) retrata su experiencia en la fábrica como una posibilidad para exponerse, pero también como un escenario en el que se llega a naturalizar el dolor, porque como ella sostiene, "las ficciones son muy poderosas en la fábrica. Hay reglas que no se observan nunca, pero que están perpetuamente en vigor" (Weil 2014, 243); Weil en sus diarios de la fábrica, insiste en mencionar un dolor de cabeza que no cesa de presentarse como una forma para silenciar el pensamiento, para no ocuparse de otra cosa más que del cuerpo dolorido y del descanso que le permite menguarlo; de esta forma el cuerpo y el pensamiento se distancian, pues los cuerpos parecer industrializar el dolor, las cicatrices, las fracturas, al punto de convertirlas en un asunto pasajero y sin importancia; en el texto de Weil, que acabamos de mencionar podemos leer:

Solo respiro el sábado por la tarde y el domingo, me encuentro a mí misma, recupero la facultad de hacer circular por mi mente pedazos de ideas. De manera general la tentación más difícil de rechazar, en semejante vida, es la de renunciar por completo a pensar: ¡sabe uno tan bien que es el único medio de no sufrir! $(2014,42)$.

Se trata, entonces de una estética empresarial del dolor, en la cual se subsiste, se naturalizan sus efectos en el cuerpo, al punto de que éstos se convierten en parte del territorio existencial de la planta, pues la subjetividad corporal, termina por ser corregida en favor de los intereses de la empresa, en diversas oportunidades escuchamos decir: "algunas nos hemos lastimado, pero no por la máquina, sino porque una se descuida un momento" (Entrevistada, comunicación personal, mayo de 2019). Reflexiones similares es posible leer en Weil:

Todo lo que es propiamente temporal se confía al objeto, y lo que depende de la pura repetición de un gesto idéntico se confía al hombre. La relación desgraciada de la conciencia y del cuerpo con el tiempo, la reclusión de la conciencia y del cuerpo en el instante, tales son las claves de la opresión en la fábrica $(2014,22)$.

Encontramos, así mismo, relaciones para nada despreciables entre ese cuerpo nuevamente escindido del pensamiento y las maneras para desaparecer de las que habla David Le Breton 
en su texto Desaparecerse de sí. Una tentación contemporánea (2017); resulta curioso que las mujeres de la planta señalen actividades cotidianas como el sueño o el descanso en sus casas, siempre vinculadas a la vida laboral; estas actividades de cierta forma se convierten en una manera de acontecer empresarial $y$, aplazamiento de la existencia propia: "durmiendo sin tregua, escapa a la historia, confiándose en una larga ausencia. Duerme para no pensar, para no decidir, para dejarse llevar de los acontecimientos" (Le Breton 2017, 49). Estas circunstancias potencian de manera permanente la ilusión de jubilación, es tanto esta dibuja una vida por venir.

No es asunto menor, el hecho que desentraman Deleuze y Guattari (2012), en el ensayo Tratado de nomadología: la máquina de guerra, acerca de la disposición que hace el Estado sobre esos cuerpos, de una violencia que no pasa por la guerra: "más que guerreros, emplea policías, carceleros, no tiene armas, ni tiene necesidad de ellas, actúa, por captura mágica inmediata, 'capta' y 'liga', impidiendo cualquier combate" (Deleuze y Guattari 2012, 360). Sin embargo, la máquina de guerra no está reducida al aparato de estado, pues traza una línea de fuga creadora, sufre constantes metamorfosis, pone a la mano otra justicia "a veces una crueldad incomprensible, pero a veces también una piedad desconocida" (360), superando la dualidad del combate. Aunque el Estado no tiene la máquina de guerra, se la puede apropiar bajo la forma de una institución como la planta de producción, en la cual los sentimientos se tornan afectos, es decir, formas de exterioridad que "atraviesan el cuerpo como flechas, son armas de guerra" (363).

De esta forma, las operarias están entre la máquina de guerra que las inspira en sus redes de relaciones (muchas de estas familiares y afectivas) y el Estado, con su orden de razones, jerarquías y actividades normalizadas en la planta de producción. El cuerpo colectivo que configuran estas mujeres se relaciona con el modelo familiar y el estatal, $y$ tal como anuncian Deleuze y Guattari (2012), "viven como 'grandes familias' de funcionarios, de empleados, de intendentes o de granjeros" (372). Sin embargo, estos cuerpos colectivos también tienen minorías que reconstituyen máquinas de guerra, aunque de maneras ambiguas. Estos autores sostienen que "el trabajador, obrero o campesino, puede reinventar una máquina de guerra" (404), a partir del surgimiento de obreros que no creen en el trabajo $y$, sin embargo, pueden llegar a ser adyacentes a una máquina.

Lo anterior, nos permite observar como los dispositivos de disciplinamiento del cuerpo, continúan haciendo presencia, desde el panóptico y la reglamentación del tiempo; y tal como lo sostiene Paula Sibilia (2010), siguiendo los planteamientos de Foucault, estos dispositivos contribuyen a administrar la vida y los cuerpos de estas personas en la fábrica: "como resultado de estos procesos, se fueron configurando ciertos tipos de cuerpos y determinados modos de ser (...) apuntaban a la construcción de cuerpos dóciles- domesticados, adiestrados, disciplinados- destinados a alimentar los engranajes de la producción fabril" (Sibilia 2010, 26).

Sibilia, alude también a un formateo, en el que se producen cuerpos útiles para la producción, capacitados, entrenados, como los de las operarias, para cargar altos volúmenes de papel u operar máquinas con nombre propio como la Tigra ${ }^{7}$, o la Guillotina, pero también, fuerzas corporales "disminuidas y subyugadas en términos políticos de obediencia" (Sibilia 2010, 27) y que terminan por reducir sus espacios vitales y de ocio, en función del empleo que les posibilita la subsistencia; en este escenario de disciplinamiento y control permanente, la

\footnotetext{
$7 \quad$ La Tigra es el nombre dado por las operarias a una Termoselladora Industrial y la Guillotina, refiere a una cortadora industrial.
} 
producción de formas de resistencia apenas es percibido, pues la exposición excesiva a los flujos que normatizan se convierten en la fuente de inspiración e incluso se asumen como ideal de vida; en este sentido, se observa que las operarias con mejor desempeño en el accionamiento de las máquinas más complejas, son las que mayor reconocimiento tienen entre sus propias compañeras de la planta, incluso a costa de que estas mismas máquinas "traguen" o "perforen" sus cuerpos, como se muestra en la Fotografía 4.

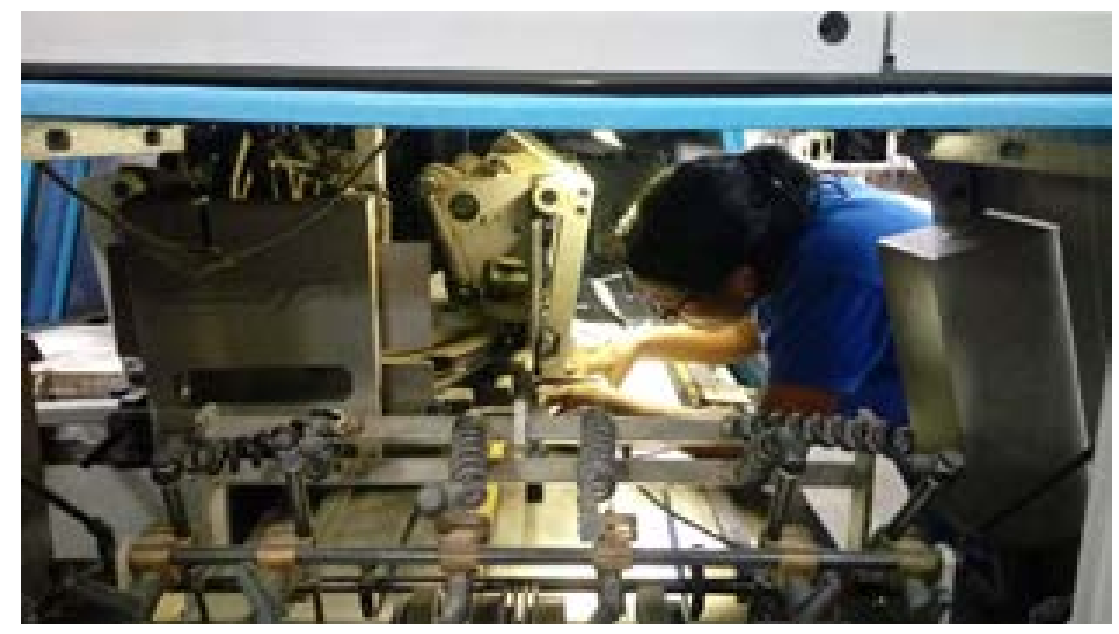

Fotografía 4. Mujer en las entrañas de la máquina, marzo de 2018. Archivo personal.

En estas corrientes de normatización de los cuerpos, las máquinas son percibidas como compañeras de labor que enseñan su funcionamiento, muestran sus engranajes, la privacidad de sus entrañas, indican cómo ser operadas y cómo relacionarse con ellas; a este proceso se refiere José Luis Pardo (2016), en estos términos:

Uno encuentra hoy, con mayor facilidad, hombres del pueblo, sin cultura ni educación, dotados sin embargo de lo que yo llamo el don de la profecía mecánica o el gusto por los metales. Son obreros que han tenido ya la educación de la máquina, que en cierto sentido están afiliados a la maquinaria (69).

Y, este mismo autor, unas líneas más adelante indica que las máquinas se convertirian en hombres y animales, que no significa negarle a los animales sensibilidad, si no que en cierto modo se entra a dotar a las máquinas de carne (Pardo, 2016). Es claro, entonces, que los modos de producción, sean estos artesanales, industriales o digitales, a través de los cuales se sustenta una sociedad, configuran sus propios cuerpos; las máquinas forman el cuerpo de quienes las operan, estas hacen que sus operarios inventen gestos, inventen su forma particular de acoplarse, mientras ésta, les indica cómo moverse, cómo accionarla, cómo entrar en contacto con ella. En la planta pudimos observar, maneras delicadas, difíciles de saber si se trataba de un gesto de limpieza o una caricia (Fotografía 5): 


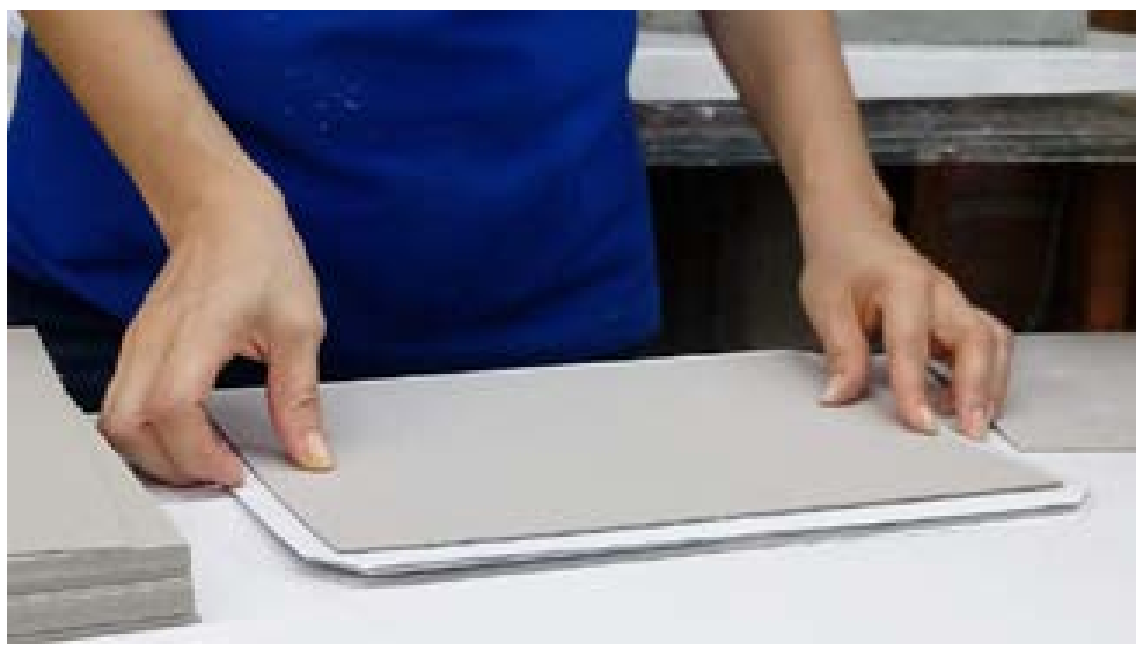

Fotografía 5. Mano araña, febrero de 2019. Archivo personal

En la búsqueda de comprensiones en torno de las maneras como se presentan los vínculos que observábamos en la planta de producción, acudimos a Fernand Deligny (2015), un autor cercano a Deleuze, cuyos planteamientos se despliegan a partir de la propuesta de mapas y de líneas de errancia, para referirse a que "la red es un modo de ser" (17). Un modo de estar que nos posibilita conectarnos, acercarnos, entre-tejernos en relaciones subjetivas; este autor sugiere que la red se traza donde falta algo, de manera que los trayectos puedan ser visualizados. El autor también se refiere a la aragne como "una auténtica fábrica incorporada en su cuerpo" (Deligny 2015, 33). Aragne que teje, que traza redes, que "crea una suerte de fuera que permite a lo humano sobrevivir" (20). En conexión con este concepto, Deleuze y Guattari (2012), proponen la idea de rizoma, el cual se compone de formas discontinuas, diversas y heterogéneas, de manera tal que un punto es la posibilidad de conexión a un número indeterminado de otros puntos.

Acorde con esas ideas, el abordaje de lo que acontece en una planta de producción, tendrá que ver, necesariamente con esas multiplicidades rizomáticas, que no se dejan codificar ni estructurar, dado que están hechas por gestos que se desplazan de forma permanente; paisaje geográfico y existencial por el que circulan experiencias, hechos históricos, epistemologías divergentes, personas, grupos, familias e incontables acontecimientos simultáneos; en este sentido nuestra presencia se suma a este movimiento. Una presencia atenta a los rastros que iban marcando los cuerpos, en las máquinas, en los muros, en los otros cuerpos; en fin, en ese paisaje geográfico y existencial que constituía la planta de producción.

En este sentido, los trazos que delineamos a continuación constituyen una cartografía de ese acontecer, una performance que dibuja los relieves del deseo, ese mismo que, en la planta de producción, adquiere tonalidades estéticas, acciones políticas, pero a veces solo gestos vitales.

\section{EL DOLOR INDUSTRIALIZADO Y SUS MARCAS}

Las maneras de accionar las máquinas han sufrido transformaciones, en la actualidad prima la digitalización, las operarias u operarios tocan algunos botones y las máquinas ejecutan los movimientos para las que han sido programas. Este universo de lo digital no requiere de grandes fortalezas musculares, las labores que demanda fuerza son puntuales en la secuencia de la 
producción. Las operarias de la planta son en su mayoría son mujeres pequeñas, pero sus manos y principalmente sus dedos índices y pulgares están hábilmente en contacto permanente con el accionar de las máquinas. El capitalismo de la fuerza muscular parece estar siendo sustituido por un capitalismo de la información, especialmente por un micro conocimiento del funcionamiento del proceso en general y de las estaciones de trabajo en particular. Este es un conocimiento que observamos, se transmite de unas operarias a otras; "he hecho como tres carreras universitarias enseñándoles a mis compañeras el oficio" (Entrevistada, comunicación personal, mayo 2019), afirmó una de las operarias que mayor tiempo lleva trabajando en la planta.

Observamos también, cierta reconfiguración de la relación con las máquinas, en este sentido, las operarias son útiles a la planta en tanto dominan el esquema completo del proceso de producción, saben desempeñarse en varios puestos de trabajo y conocen los tiempos de inicio y entrega de un determinado producto. Las planillas del supervisor con sus cifras, gráficas y cronogramas constituyen un cuerpo parlante, un jefe codificado a través de un conjunto de consignas. El cuerpo de la operaria y la máquina aguardan órdenes, procesan códigos complejos que se traducen en una operación. La manera en que las operarias hablan de las máquinas, los nombres que les ponen, nos conducen a pensar en máquinas vivas, con una potencia subjetiva de sus movimientos, los mismos que parecen marcar otro matiz a una rutina productiva que se torna inacabable.

Los pedidos que llegan a la planta, provenientes del área comercial, son corporizados por las operarias, el supervisor da instrucciones y ellas hacen de ese pedido un propósito, ${ }^{8}$ en cuestión de minutos las consignas, pasan a

$8 \quad$ En la planta escuchamos discursos administrativos, que aluden a la gerencia de procesos, a la autonomía de los trabajadores y al compromiso con los procesos de productividad de la empresa. ser códigos digitados en las cortadoras, en las impresoras, en las termo selladoras, en las encuadernadoras; en fin, cuerpos y máquinas en armónica cooperación hacen su trabajo. Atada a su collar electrónico, la consigna, monitorea cada movimiento y mide el tiempo justo para llevar a cabo una tarea. Los modos en los que se va produciendo el dolor en la planta son sutiles y lentamente van agujerando el movimiento de la vida, esas líneas curvas que la conforman.

Las instrucciones activan fuerzas que actúan sobre el cuerpo y las máquinas; estas instrucciones van desplegándose por capas sucesivas, agentes comerciales, personal administrativo, hasta llegar finalmente, a constituir la operación de la planta; luego, los productos que son fabricados en la planta hacen el recorrido inverso. En todo este camino de ida y vuelta, observamos pliegues diversos de formación corporal; "en el caso de lo viviente hay un pliegue formativo interior que se transforma con la evolución, con el desarrollo del organismo; de ahí la necesidad de una performación" (Deleuze 2017, 16). Esta circulación de fuerzas instructivas y formativas, a la vez, da cuenta de la acción maquínica que se produce en la planta de producción, la cual posee una determinación que le posibilita transferirse de un eslabón a otro, hasta constituir, una operación sistemática que no encuentra reposo.

El cuerpo performado que configuran las operarias y las máquinas que ellas operan, crean sus propias maneras de desenvolverse, ya no como acción repetitiva de tensión y distensión muscular, sino como un quehacer que pliega el propio cuerpo a la cadena productiva. En este mismo sentido, el dolor se presenta polifónicos, un paisaje sonoro que incorpora sonidos disímiles a la producción. Los cuerpos se despliegan en una figura que se acerca a la de las semillas: "la primera mosca contiene todas las moscas futuras, estando cada una destinada a su vez a desplegar sus propias partes, llegado 
el momento" (Deleuze 2017, 18). En cada operaria están los pliegues de las demás; estos cuerpos, se mueven por la planta, no como unidades orgánicas, sino como multiplicidades que agencian la productividad.

Con frecuencia observamos que sus cuerpos se posan sobre las máquinas, parecen fusionarse, de manera que todo el peso de sus vidas es puesto sobre estas (Fotografía 6. Plegadora tragando el cuerpo de una operaria, marzo de 2018). Estos cuerpos que reposan pueblan y animan la planta de producción. Las máquinas por su parte, acogen los cuerpos de las operarias, se dejan afectar, se gastan más en aquellos lugares donde se produce el contacto. En las conversaciones, aparece de formar reiterativa el dolor de los pies, del antebrazo, el índice que presiona el papel y los dedos cortados por el roce del papel. Duelen también las abolladuras, las astillas partidas, las marcas en la piel de las máquinas; una máquina rota, produce rompimientos en las rutinas cotidianas de quienes la operan.

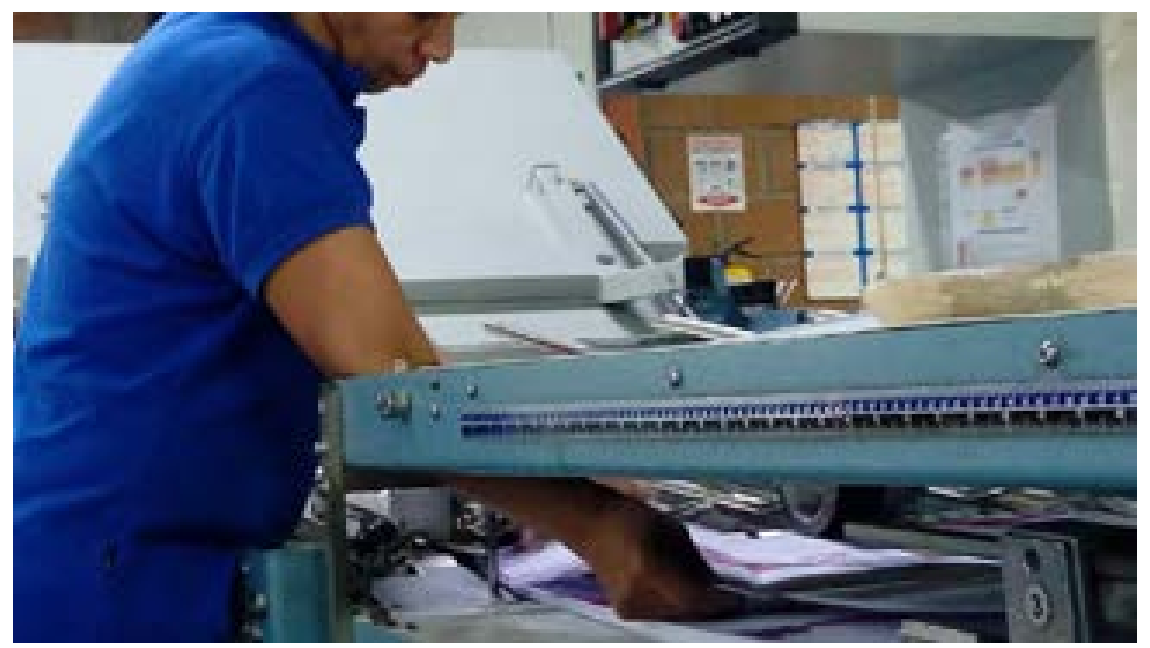

\section{Fotografía 6. Plegadora tragando el cuerpo de una operaria, marzo de 2018. Archivo personal.}

Encontramos que los dolores que se producen en la planta de producción tienen diversidad de maneras de inscribe en los cuerpos, algunos se subjetivan a través de movimientos de resistencia a las lógicas de funcionamiento de la máquina; pero también se producen en la correspondencia del cuerpo a la demanda de la máquina, pues cada máquina exige una postura determinada, la que a su vez recae sobre un área específica del cuerpo. George Vigarello, (2005), percibe un carácter pedagógico de la postura y, concluye que la "lenta instalación del mundo industrial hace surgir la visión de la eficiencia de los gestos, movimientos y actitudes ante los cuales las descripciones de la postura, así como la de su pedagogía, no pueden resultar ajenas" (43). Tan lenta como la instalación a la alude Vigarello, es la acción performática de la postura que se transforma en dolores crónicos.

En la misma dirección de Vigarello, va el estudio de Pascal Ory (2006) en el que se evidencian, entre otras cosas, una pregunta insistente por el desgate corporal; por el cuerpo en el trabajo y las violencias que allí se suceden; este estudio nos permite ahondar en la pregunta por el deterioro del cuerpo y la configuración de una gramática del sufrimiento; observamos que, en la planta de producción, esta gramática, parece formarse a través de una sumatoria de fuerzas, ejercidas sobre otros cuerpos-máquinas $y$, apropiadas simultáneamente, en el contacto 
con las materialidades que pasan al cuerpo y ejercen su propio peso, un peso molecular que construye un acontecer doliente.

Supimos que, en la planta, los dolores intensos y devastadores llegan justo cuando el cuerpo de la operaria se expande distraído, entonces la máquina reclama un órgano para sí, o bien abre grietas por las cuales penetrar en los cuerpos. Este tipo de acontecimientos no son frecuentes, pero cada una de las operarias tuvo una historia que contar, al respecto de las marcas que llevan en sus cuerpos; cicatrices dejadas principalmente por la Termo selladora.

Indagando en los tiempos en que se producen los accidentes laborales, nos contaron que estos ocurren cuando las operarias están solas, no recordaban que hubiese ocurrido un accidente cuando algunas de las compañeras de trabajo se acercan a preguntar o conversar, mientras se trabaja. Lo anterior nos llevó a pensar en un cuerpo-red de afectos, en el cual el dolor y las marcas que le acompañan se construyen subjetivamente a través de los roces diarios de los otros cuerpos y las máquinas; cuerpos y máquinas, danzan, una tensa coreografía, con dolores rítmicos de fondo.

\section{SUFRIR Y AGRADECER: UNA ACCIÓN CONSTITUTIVA DE LA EXISTENCIA}

Algunas de las operarias, llegaron jóvenes a la planta: "todas llegamos a esa edad", dijo una de ellas, mientras señalaba a una joven aprendiz, de unos 17 o 18 años, sobrina de una operaria que se jubiló cinco meses atrás. A través de las conversaciones cotidianas, supimos que la mayoría de ellas dejaron apresuradamente la niñez, la casa de los padres y un tanto desterradas de sí mismas, iniciaron una vida en la planta, a fuerza de rutina fueron creando un nuevo territorio para la existencia, uno que también les es esquivo.
En este paisaje geográfico y existencial que configura la planta de producción, percibimos una economía del sufrimiento, en la cual, cada situación es cuidadosamente sopesada y se elige aquella que se cree constituye un grado menor de sufrimiento. En las narraciones que hacen de sus experiencias, los hechos dolorosos son los nudos que atan la vida que se han creado; "la memoria se extiende dentro del material mismo de la cuerda, en las torsiones y flexiones de sus fibras constituyentes" (Ingold 2018, 51); la descripción de Ingold nos da una pista importante acerca de la forma de este movimiento subjetivo. Notamos que este movimiento a veces les toma por sorpresa, y un aire de nostalgia bordea las conversaciones, no es un sentimiento respecto de una pérdida, se trata más bien, de una experiencia en la cual el sufrimiento se experimenta como una acción constitutiva de la existencia; "a esta vida hemos venido a sufrir”, escuchamos de forma reiterada.

Es cierto que la planta de producción les ha proporcionado una nueva manera de constituirse subjetivamente, pero esta es una operación que las deja en deuda, pues esta subjetividad de operaria eficiente es la que alimenta la producción; las vidas que han constituido son justamente, unas que favorecen a la planta de producción.

Maurizio Lazzarato, (2013), en La fábrica del hombre endeudado, sugiere que en el fundamento de estas relaciones "no se halla el intercambio, sino una relación de poder asimétrico entre acreedor y deudor" (83). El trabajo en la planta se constituye en la manera de proveer sustento económico, pero a la vez, esta actividad dominante da forma a la existencia, se convierte en el sentido de sus vidas. Nos encontramos con un reiterado e insistente agradecimiento por esa vida que la planta les ha proporcionado; observamos aquí la operación de un mecanismo de subjetivación a través del cual, en la medida que ellas se hacen cargo de 
su propia subjetividad, se hacen cargo de la planta de producción. A este respecto Lazzarato plantea que

Una lectura no economicista de la economía significa, por un lado, que la producción económica es indisociable de la producción y el control de la subjetividad y sus formas de existencia, $y$, por el otro, que la moneda, antes de cumplir las funciones económicas de medida, medio de intercambio, pago y atesoramiento, es expresión de un poder de mando y distribución de lugares y tareas de los gobernados $(2013,83)$.

La perspectiva de Lazzarato, nos conduce a pensar que existen profundas desigualdades entre la oferta de trabajo que propone el sector de la industria y la vida que operarias y operarios entregan a sus plantas de producción; en ello no hay elección ni preparación de orden profesional. En este sentido Lazzatato (2013), considera que se producen unas relaciones estratégicas donde moneda y cuerpo se intercambian, es decir, "cantidades de potencia diferentes" (86). Lo que notamos es que las personas necesitan con urgencia resolver su sustento económico, razón que les lleva a aceptar ser entrenados y trabajar, agradecidos, por lo que llaman una "oportunidad laboral". Obviamente, tener cómo sustentarse es preferible a no tener nada; esto nos permite entender que las operarias, por ejemplo, minimicen las condiciones en que las realizan sus labores; por ejemplo, trabajar largas jornadas en una bodega con calor extremo en ciertas horas del día, además de una escasa ventilación.

Atendiendo los análisis de Lazzarato, quien a su vez se apoya conceptualmente en Deleuze, se comprende que en estas condiciones existenciales de desigualdad se despliega un ejercicio de subjetivación, en el cual, más que un intercambio propiamente económico; lo que se escenifica es la presencia de una potencia que impulsa a darse, a subordinare ante los influjos de la planta de producción. Lazzarato, considera que el empleador dispone del tiempo "como decisión, como elección, como posibilidad de explotar, someter, mandar, dirigir a otros hombres" $(2013,96)$ y es este tiempo (48 horas a la semana), el que se tasa y se paga a las operarias.

En el plano contractual, se intercambia tiempo por salario, pero en el día a día lo que circulan son procesos de subjetivación que devienen cuerpos que instruyen y son instruidos, acciones de mando y de obediencia; aquí radica la potencia de la planta de producción, potencias que observamos sustentadas en multiplicidad de mediciones del rendimiento, consignado en las minutas semanales y los registros diarios, así como el seguimiento a los pedidos.

Estos sofisticados mecanismos de medición y de control suelen dejar abiertas microporosidades a través de las cuales las operarias, mediante gestos casi imperceptibles, transforman sus (Fotografía 7. Huellero comunitario, 2019). Aquí percibimos la creación micro resistencias, es decir, formas inusitadas de intervenir en la cadena de producción establecida, de modo que la planta adquiere una dimensión familiar por la que circulan afectos de todo tipo, al punto que pareciera convertirse en su hogar, pues, al hogar propio, van solo a reposar el cansancio y reponer las energías necesarias para volver a trabajar al día siguiente. 


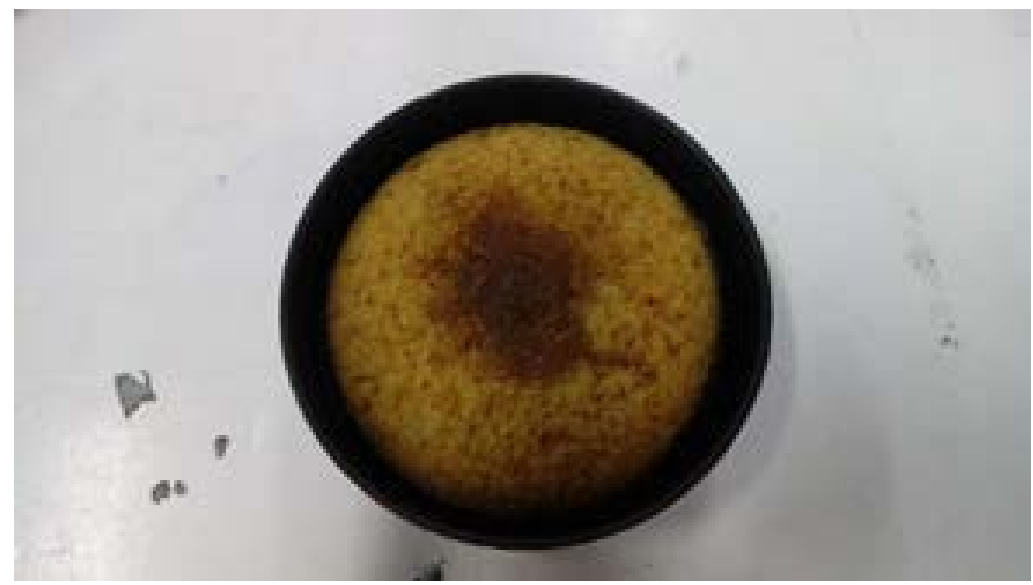

Fotografía 7. Huellero comunitario, 2019. Archivo personal.

\section{DISCURRIR SENSIBLE EN LA PLANTA DE PRODUCCIÓN}

Transitar lo cotidiano, recorrer juntos los espacios, desplazamiento atente en la planta de producción, detener-nos en los lugares indicados de paisajes. Las acciones cartográficas del paisajear la planta derivan invitación a recorrer los caminos simples y vitales de quienes la habitan. Seguir la pista al despliegue subjetivo de un accidente en la vía pública, ¿quién es ahora el sobreviviente? ¿Cómo hacer para seguir viviendo luego de la muerte violenta de los seres queridos? ¿Qué hacer con esa especie de "destierro" recurrente? La planta de producción está surcada de cuerpos desahuciados por el dolor; sin embargo, este dolor rancio, que se niega a desaparecer y agencia potentemente la vida de las operarias.

Observamos que ciertos sufrimientos se convierten en agentes que se posicionan de los cuerpos y los fuerzan a seguir allí, para conseguir una casa propia, decisión que parece encarnar la posibilidad de construcción de un nuevo territorio existencial para sí mismas y la familia que han construido o reconstruido. Padecer hambre y sobrepasar las adversidades, son experiencias que se valoran en función de su contribución a la ganancia de fortaleza para nuevos infortunios, pues el existir, está claramente asociado a ello.

Laplanta de producción en tanto cuerpo-maquina, está salpicada de fragmentos de historias de mujeres, historias de las fuerzas que recorren las periferias de la ciudad y de otras zonas de la región; eso hechos se reconfiguran ahora en una estructura corporal que agencia en tanto es agenciada, flujos y reflujos de un ecosistema empresarial. No se trata de una acción simple: una obrera que opera una máquina; pensamos, más bien, en un ecosistema en cual el cuerpo y la máquina forman el artefacto de la producción; artefacto maquínico que se vale de lo que hay, -por supuesto se nutre también del sufrimiento y del dolor- para accionar un mecanismo incansable en el que se producen materialidades y subjetividades.

La maquínica empresarial envuelve los cuerpos a la vez que los despliega en sus capas, por eso logra habilitar $y$ habitar de forma excepcional todos los espacios de la vida de las operarias, y les proporciona dar expresión a un universo que ellas desconocen de sí mismas. Nos referimos a historias de mujeres que pasan de ser maltratadas a ganar su propio dinero; a historias reiteradas de desplazamientos, que ahora cuentan con un trabajo y un lugar propio en el cual habitar. Por supuesto, no nos interesa 
cuestionar lo importante que resulta acceder a un trabajo que posibilita la transformación de las condiciones de vida, pero no podemos dejar de marcar esos otros efectos-afectos que el artefacto empresarial contemporáneo pone en circulación.

\section{A MODO DE CONCLUSIONES}

En este artículo, situamos en contexto (una planta de producción), cierta industrialización del dolor y registramos la diversidad de maneras de escribirse (performar) en el cuerpo. Este es un dolor que no cabe en los nombres otorgados por esa industria, más o menos reciente de la seguridad industrial, también llamada medicina laboral; percibimos que este no es un dolor monocromático, al contrario, este posee una impresionante gama de tonalidades. Es un dolor sin órganos, más cercano a una gramática corporal, que a lo que conocemos como enfermedad, pero que, al operar de manera gramatical, performa todo lo que toca.

La gramática del dolor está asociada a unas formas de cansancio industrializadas. Los cuerpos se agotan e inventan maneras de resistir a ese agotamiento. Los cuerpos cansados que duermen en el transporte público y a veces se pasan de la estación de destino. Los cuerpos que caen días enteros sobre el teclado de las máquinas o computadoras propias del paisaje pandémico. Este es un agotamiento que va dando forma al cuerpo y pareciera provenir del ruido que produce el mismo proceso empresarial penetrando la piel, los músculos, los huesos, la médula, los órganos blandos, pues parece no haber lugar inalcanzable. La intensidad del proceso de producción deja registros en forma de cicatrices, deformaciones, dolencias crónicas. Esas marcas no se sitúan en un lugar específico, están dotadas de movilidad, se desplazan por los cuerpos y desencadenan otros movimientos; percibimos una reinvención subjetiva en y a través de las marcas que las máquinas de la planta van dejando en los cuerpos.
En esta planta de producción, visualizamos desde un contexto singular, el tránsito, o más bien, las superposiciones de sociedades disciplinares y sociedades de control, en esa simbiosis nos encontramos con unos cuerpos que ya no responden a la idea del "obrero de la fábrica". La particularidad de los cuerpos industrializados que visualizamos da cuenta más bien, de una experiencia corporal; esto es, cuerpos-máquinas y subjetividades ecoempresariales. En la planta de producción se producen materiales educativos, pero también se producen modos de subjetivación (modos de estar en el mundo), modos de educar los cuerpos fabricados en la gran fábrica de capitalismo.

Observamos, entonces, que la planta de producción agencia de forma singular, pero suponemos que de la misma manera lo hacen otras plantas y otras fábricas, porque los flujos y reflejos de la productividad empresarial contemporánea responden a un modo de producción, que produce y transforma materialidades y subjetividades, lo que podríamos llamar subjetividades de una producción y reproducción que no cesa de producirse.

\section{REFERENCIAS BIBLIOGRÁFICAS}

Bal, Mieke. (2016). Tiempos trastornados. Análisis, historia y políticas de la mirada. Madrid: Ediciones Akal.

Braidotti, Rossi. (2018). Por una política afirmativa. Itinerarios éticos. Barcelona: Editorial Gedisa.

Braidotti, Rossi. (2015). Lo posthumano. Barcelona: Editorial Gedisa.

Berger, Peter, y Luckmann, Thomas. (2001). La construcción social de la realidad. Buenos Aires: Amorrortu editores. 
Courtine, Jean.-Jacques. (ed.) (2014). Historia del cuerpo, T. III, El siglo XX, Trads. A. Martorell, M. Rubio. Madrid: Taurus.

Deleuze, Gilles. (1995). Conversaciones. Valencia: Pre-Textos.

Deleuze, Gilles. (2017). El Pliegue. Leibniz y el Barroco. Barcelona: Paidós básica.

Deleuze, Gilles y Guattari, Félix. (2012). Mil mesetas. Capitalismo y esquizofrenia. Valencia: Pre-Textos.

Deligny, Fernand. (2015). Lo arácnido y otros textos. Buenos Aires: Cactus.

Dias, B. e Irwin, Rita. (Org.). (2013). "A/r/tografia como metodologia e pedagogía em artes: uma introdução". En: Pesquisa Educacional Baseada em Arte: A/rl tografía. Santa María: Editora UFSM.

Foucault, Michel. (2002). Vigilar y Castigar. Nacimiento de la Prisión. Buenos Aires: Siglo XXI.

Guattari, Félix y Rolnik, Suely. (2006). Micropolítica. Cartografías del deseo. Madrid: Traficantes de sueños.

Ingold, Tim. (2018). La vida de las líneas. Santiago de Chile: Ediciones Universidad Alberto Hurtado.

Lazzarato, Maurizio. (2013). La fábrica del hombre endeudado. Ensayo sobre la condición neoliberal. Buenos Aires: Amorrortu editores.

Le Breton, David. (2017). Desaparecerse de sí. Una tentación contemporánea. Madrid: Siruela.

Ory, Pascal. (2006). "El cuerpo ordinario". En Historia del cuerpo. Volumen III. Las mutaciones de la mirada. El siglo XX. Madrid: Taurus.
Ospina, Teresita, Hernández, Edilberto y Farina, Cynthia. (2019). Afecciones corporales en una planta de producción de materiales educativos. Revista da FAEEBA Educação e Contemporaneidade, v. 28, n. 56, p. 185. https://bit.ly/3b5mKls

Pardo, José Luis. (2016). Estética de lo peor. De las ventajas e inconvenientes del arte para la vida. Madrid: Pasos perdidos.

Serres, Michel. (2011). Variaciones sobre el cuerpo. Buenos Aires: Fondo de Cultura Económica.

Sibilia, Paula. (2010). El hombre postorgánico. Cuerpo, subjetividades y tecnologías digitales. Buenos Aires: Fondo de Cultura Económica.

Vigarello, George. (2005). Corregir el cuerpo: historia de un poder pedagógico. Buenos Aires: Nueva visión.

Weil, Simone. (2014). La condición obrera. Madrid: Trotta. 